\title{
Estudio histoquímico e inmunotipificación de poblaciones leucocitarias del timo de alpacas (Vicugna pacos) menores a 60 días de edad
}

\author{
Histochemical study and immunotyping of thymus leukocytic populations of alpacas \\ (Vicugna pacos) younger than 60 days of age
}

Ricardo Grandez R. ${ }^{1,2,3}$, Javier Mamani P., ${ }^{1,2}$, Christian Pitot A. ${ }^{1,2}$, Roy Andrade E. ${ }^{1}$

\section{Resumen}

\begin{abstract}
El objetivo del estudio fue identificar las poblaciones leucocitarias en el timo posnatal de alpacas menores de 60 días de edad. Se realizó la eutanasia a seis alpacas Huacaya en la provincia de Huanta, Ayacucho, Perú. Se obtuvieron muestras de timo que fueron embebidas en OTC y congeladas inmediatamente en nitrógeno líquido y conservadas a $-70{ }^{\circ} \mathrm{C}$ hasta su procesamiento. Se prepararon secciones congeladas y se fijaron a la lámina con el adhesivo organosilano. Se realizó la inmunohistoquímica con anticuerpo primario de ratón y secundarios de conejo. La reacción se evidenció empleando el complejo avidina-biotina-peroxidasa y se contra-coloreó con Hematoxilina. Se emplearon anticuerpos monoclonales específicos para la identificación de las subpoblaciones leucocíticas del timo; se evaluaron cinco campos visuales de forma aleatoria a un aumento de 400X. La distribución y densidad de la tinción se clasificó como negativa (-), inconstante $( \pm)$, ligera $(+)$, moderada $(++)$ y fuerte $(+++)$. Los resultados muestran que la mayor población de células leucocitarias se ubicó en la corteza del timo y correspondieron a células inmaduras que no expresan marcadores de superficie; así mismo, la mayor población de células inmunomarcadas, en maduración, se ubicaron en la médula del timo, predominando los linfocitos TCR $\alpha \beta$, con valores bajos de linfocitos TCR $\gamma \delta$, linfocitos CD8, linfocitos B y monocitos/macrófagos, con valores inconstantes de linfocitos CD4. En la corteza del timo se observaron valores bajos de linfocitos TCR $\alpha \beta$ y linfocitos CD8, $\mathrm{y}$ valores inconstantes de monocitos/macrófagos, sin evidencias de linfocitos TCR $\gamma \delta$, linfocitos CD4 y linfocitos B.
\end{abstract}

Palabras clave: Vicugna pacos; timo; leucocitos; inmunotipificación; histoquímica

${ }^{1}$ Sección de Biociencias y Ciencias Clínicas, Departamento Académico de Medicina Veterinaria y Zootecnia, Facultad de Medicina Veterinaria y Zootecnia, Universidad Peruana Cayetano Heredia, Lima, Perú

${ }^{2}$ Laboratorio de Histología y Patología Veterinaria, Facultad de Medicina Veterinaria y Zootecnia, Universidad Peruana Cayetano Heredia, Lima, Perú

${ }^{3}$ E-mail: rgrandez@hotmail.com

Recibido: 19 de noviembre de 2018

Aceptado para publicación: 14 de junio de 2019 
The objective of the study was to identify leukocyte populations in the postnatal thymus of alpacas under 60 days of age. Euthanasia was performed on six Huacaya alpacas in Huanta province, Ayacucho, Peru. Thymus samples were obtained, embedded in OCT and immediately frozen in liquid nitrogen and stored at $-70{ }^{\circ} \mathrm{C}$ until processing. Frozen sections were prepared and mounted with organosilane. Immunohistochemistry was performed with mouse primary antibody and rabbit secondary antibodies. The reaction was evidenced using the avidin-biotin-peroxidase complex and was counter-stained with hematoxylin. Specific monoclonal antibodies were used for the identification of leukocytic subpopulations of the thymus. Five visual fields were randomly evaluated at $400 \mathrm{X}$. The distribution and density of the staining was classified as negative (-), inconstant $( \pm)$, slight $(+)$, moderate $(++)$ and strong $(+++)$. The results show that the largest population of leukocyte cells was located in the cortex of the thymus and corresponded to immature cells that do not express surface markers; likewise, the highest population of immunomarked cells, in maturation, were located in the medulla of the thymus, predominantly the TCR- $\alpha \beta$ lymphocytes, with low values of $\gamma \delta$ TCR lymphocytes, CD 8 lymphocytes, B lymphocytes and monocytes/macrophages, with inconstant lymphocyte values CD4. In the cortex of the thymus there were low values of $\alpha \beta$ TCR lymphocytes and CD8 lymphocytes, and inconstant values of monocytes/macrophages, without evidence of $\gamma \delta$ TCR lymphocytes, CD4 lymphocytes and B lymphocytes.

Key words: Vicugna pacos; thymus; leukocytes; immunotyping; histochemistry

\section{INTRODUCCIÓN}

El Perú es el principal productor de camélidos sudamericanos (CSA) del mundo, con más de 4.4 millones de cabezas entre alpacas, llamas, vicuñas y guanacos, distribuidas principalmente en la Sierra, con 3685000 cabezas. La crianza de alpacas en la zona altoandina del Perú es una actividad socioeconómica de gran importancia; sin embargo, las elevadas tasas de mortalidad por causas infecciosas, principalmente en crías, constituyen un factor limitante en su crianza (Ameghino, 1991; Rosadio et al., 2012). Los resultados del último Censo Nacional Agropecuario, llevado a cabo en 2012, muestra que la población de alpacas aumentó en $50.2 \%$ la población registrada en el censo de 1994 (INEI, 2012).

El sistema inmune de la alpaca es muy similar en composición al de los rumiantes, con capacidad de responder a distintos agentes infecciosos (Davis et al., 2000). Se ha caracterizado la histología del desarrollo fetal del bazo y el timo en alpacas (Montenegro et al., 2006; Arias et al., 2011), así como la histología y la dinámica linfoide de las Placas de Peyer en neonatos de alpacas menores de 45 días (Roca et al., 2014).

El timo es el primer órgano linfoide que se forma durante el desarrollo fetal. Se origina en la tercera y cuarta bolsa faríngea, y se diferencia de otros órganos linfoides porque contiene células provenientes de distintas láminas embrionarias: endodermo, mesodermo y ectodermo (Carlson, 1990; Noden y De Lahunta, 1990; Chilmonczyk, 1992). El desarrollo del timo embrionario y fetal en la alpaca sigue un patrón similar al de las especies de rumiantes domésticos. Es así que a los 40 días de edad gestacional se observa un rudimento tímico, entre los 100 y 130 días se define la corteza y la médula, y a partir de los 100 días de edad se evidencian los corpúsculos de Hassal en la médula tímica, llegándose a observar algunos nidos celulares eritroblásticos (Montenegro et al., 2006). 
Estructuralmente, el timo presenta lóbulos rodeados por una fina capa de tejido conjuntivo que se continúa con finos septos que dividen los lóbulos en lobulillos; cada uno de ellos comprende una región periférica o zona cortical externa, corteza, y una región interna, médula. La corteza está poblada por abundantes timocitos y en menor proporción células epiteliales reticulares grandes. La médula presenta similar conformación celular, pero con menor densidad celular, y se observa células reticulares epiteliales queratinizadas conformado los denominados corpúsculos de Hassal (Dellmann y Brown, 1980; Montenegro et al., 2006). El estroma está conformado por una red tridimensional de tejido conjuntivo, que incluye la cápsula, trabéculas y una fina red de fibras reticulares. Los tipos celulares presentes en el timo incluyen a los timocitos o linfocitos, las células epiteliales reticulares o células epiteliales tímicas, las células dendríticas interdigitantes y los macrófagos (Montenegro et al., 2006; Latre y Bárcena, 2007).

La distribución de los linfocitos en el timo corresponde a un $88 \%$ en la corteza y $12 \%$ en la médula. Asimismo, mediante la identificación de marcadores antigénicos de superficie se diferencian poblaciones de linfocitos $\mathrm{CD} 8^{+}$(citotóxicos) y linfocitos $\mathrm{CD} 4^{+}$(colaboradores) o simples positivos (SP) a nivel de la médula tímica, en tanto que en la corteza se observan linfocitos $\mathrm{CD}^{+}$y $\mathrm{CD} 4^{+}$, doble positivo (DP), y los linfocitos CD8- o CD4, doble negativo (DN) (Shortman, 1985; Vaidya et al., 2016). Godderis (1989) describe en terneros que la mayor población de células en el timo corresponde a los linfocitos $\mathrm{T}(97 \%)$, con una discreta población de células dendríticas (3\%), indicando que los linfocitos predominantes en la corteza tímica corresponden a los triples positivos (TP) $\mathrm{CD}^{+}$ $\mathrm{CD}^{+} \mathrm{CD}^{+}(50$ a $60 \%$ ), sobre los triples negativos (TN) CD2- CD4- CD8- (10 a 20\%); en tanto que en la médula tímica predominan los simples positivos $\mathrm{CD}^{+}, \mathrm{CD}^{+}$y TCR $\gamma \delta$ (5 al 15\%).
La respuesta inmune en las diferentes especies animales es similar, pero no idéntica; observándose diferencias en la composición y frecuencia de las subpoblaciones de linfocitos, de allí que se debe tener en cuenta estas consideraciones cuando se analiza la respuesta inmune a patógenos o vacunas (Davis y Hamilton, 2006). Asimismo, se ha descrito en ratones de laboratorio la remodelación de las subpoblaciones de linfocitos en tejidos linfáticos y sangre periférica, observándose cambios sustanciales en estas poblaciones en relación a la edad (Capri et al., 2000).

En la actualidad se dispone de métodos que permiten diferenciar y cuantificar las poblaciones leucocitarias, como es la técnica inmunohistoquímica. Esta técnica identifica células en tejidos, frotis y cortes histológicos mediante anticuerpos específicos contra antígenos de superficie formando complejos antígeno-anticuerpo (Davis et al., 2000; Davis y Hamilton, 2006; Haynes y Fauci, 2006). Estas reacciones se hacen visibles mediante marcadores enzimáticos, peroxidasa o fosfatasa alcalina, y generan color sobre un sustrato incoloro (Enciso, 1995). Con base a estos antecedentes, se implementó este estudio con el fin de identificar las poblaciones leucocitarias en el timo posnatal de alpacas menores de 60 días de edad.

\section{Materiales y Métodos}

\section{Muestras Biológicas}

Las muestras de tejidos provinieron del banco de especímenes de órganos del Proyecto «Estudio histoquímico e inmunohistoquímico del sistema linfático de la alpaca» desarrollado por el Laboratorio de Histología y Patología (LHP) de la Facultad de Medicina Veterinaria y Zootecnia (FAVEZ) de la Universidad Peruana Cayetano Heredia (UPCH), Lima, Perú. 
Cuadro 1. Anticuerpos monoclonales (AcM), isotipo, cúmulo de diferenciación (CD) y patrón predominante de expresión celular empleado en la identificación de poblaciones leucocitarias en timo de alpacas (Vicugna pacos) menores de 60 días de edad

\begin{tabular}{lccl}
\hline Ac M & Isotipo & CD & Patrón predominante de expresión celular \\
\hline TH14B & IgG2a & MHC II & $\begin{array}{l}\text { Linfocitos B, monocitos/macrófagos, linfocito } \\
\text { T activado }\end{array}$ \\
GC50A & IgM & LaCD4 & Linfocitos T CD4 (cooperadores) \\
CAM36A & IgG1 & LaCD14 & Monocitos/macrófagos \\
GB45A & IgG1 & BoWC1 & Linfocitos TCR $\gamma \delta$ \\
DH59B & IgG1 & SWC3 & Granulocitos, monocitos/macrófagos \\
LT10A & IgG2a & Lc1 & Linfocitos TCR $\alpha \beta$ \\
LT97A & IgG2b & Lc2 & Granulocitos, monocitos/macrófagos \\
LH41A & IgM & - & Linfocitos TCR $\alpha \beta$ \\
KT5A & IgG2a & LaCD8 & Linfocitos TCR $\alpha \gamma \delta$ \\
H58A & IgG2a & MHC I & Pan leucocitos y plaquetas \\
\hline
\end{tabular}

Las muestras fueron obtenidas en el distrito de Huanta, provincia de Huanta, departamento de Ayacucho, Perú. Se colectaron muestras de timo de seis alpacas Huacaya menores de 60 días de edad, que fueron identificadas por su fenotipo característico (De Lamo, 2011). Para esto, los animales fueron previamente eutanasiados con pentobarbital sódico a dosis de $200 \mathrm{mg} / \mathrm{kg}$ (Bolant et al., 1990), procedimiento previamente aprobado por el Comité Institucional de Ética para el Uso de Animales de la UPCH.

Las muestras de tejidos obtenidas en campo fueron embebidas en OTC (Medium Optimal Cutting Temperature, Laboratorios Miles, Elkhart, EEUU) y congeladas inmediatamente en campo en un tanque de nitrógeno líquido $\left(-196^{\circ} \mathrm{C}\right)$, para luego ser almacenadas en congelación a $-70^{\circ} \mathrm{C}$ hasta su procesamiento.

\section{Lugar de Ejecución y Procesamiento}

Las muestras fueron procesadas en el LHP-FAVEZ. Inicialmente, las muestras fueron sometidas a criosección de $6 \mu \mathrm{m}$ de grosor con el uso del criostato LEICA CM 1100.
Los cortes fueron colocados en láminas portaobjetos con Poli-L-Lisina, secados y sumergidos en alcohol absoluto por 8 minutos $\mathrm{y}$, posteriormente, secados a temperatura ambiente. Se prepararon 10 láminas de cada timo y se analizaron mediante la técnica de inmunohistoquímica. Las imágenes fueron evaluadas con un microscopio Zeiss Axiostar, vinculado a una cámara Axioscam MRcS5 unido a un Tri-ocular Zeiss para el registro de las imágenes.

\section{Anticuerpos Monoclonales (AcM)}

Los anticuerpos monoclonales usados se muestran en la Cuadro 1. Así mismo, se utilizaron reactivos provenientes del Monoclonal Antibody Center, Department of Veterinary Microbiology \& Pathology, College of Veterinary Medicine, Washington State University, USA, recibidos como parte de las actividades del proyecto maestro.

\section{Prueba de Inmunohistoquímica (IHQ)}

Se prepararon secciones congeladas del timo y se fijaron a la lámina con el adhesivo organosilano [(3-aminopropyl)-triethoxy- 
silane]. Luego, el tejido cortado se secó con aire frío y se fijó con etanol absoluto durante 8 minutos. Las secciones del tejido se preincubaron en suero equino al $10 \%$ durante 30 minutos, para bloquear la unión no específica del anticuerpo secundario a los elementos del tejido.

Posteriormente se hizo reaccionar los cortes de tejido con el anticuerpo primario de ratón, durante una noche a $4{ }^{\circ} \mathrm{C}$. Se enjuagó tres veces con PBS a temperatura ambiente y luego se hizo reaccionar los cortes de tejido con los anticuerpos secundarios de conejo (diluidos con PBS, 1:100) y la biotina conjugada durante una hora a temperatura ambiente. Se enjuagó por tres veces con PBS a temperatura ambiente; se inactivó la peroxidasa endógena, incubando con $\mathrm{H}_{2} \mathrm{O}_{2}$ /metanol al $0.3 \%$ por 30 minutos, y se enjuagó por tres veces con PBS a temperatura ambiente.

Se hizo reaccionar los cortes de tejido con el complejo avidina biotina - peroxidasa (ABC - peroxidasa; Vector Labs) por 30 minutos a temperatura ambiente, se enjuagó por tres veces con PBS a temperatura ambiente. Luego se reveló con $\mathrm{H}_{2} \mathrm{O}_{2}$ al $0.01 \%$, 3,3-diaminobenzidina $0.05 \mathrm{M} \mathrm{al} 0.02 \%$ y Tris buffer (pH 7.6) conteniendo $10 \mathrm{mM}$ de azida sódica; se enjuagó con Mili Q o el equivalente purificado de agua y finalmente se contracoloreó con hematoxilina para evaluar la arquitectura citotisular del timo.

\section{Láminas Procesadas con IHQ}

Las láminas fueron examinadas con microscopía de luz y digitalizadas. Se evaluó semicuantitativamente la cantidad de células inmunomarcadas de la zona cortical y zona medular para los AcM empleados. Las láminas fueron codificadas para identificar el AcM usado para evitar que el revisor disponga de este conocimiento (estudio al azar ciego simple). Se evaluaron cinco campos visuales de forma aleatoria a un aumento de 400X para cada AcM.
La distribución y densidad de la tinción de células positivas se determinó empleando los criterios adaptados de Galeotti et al. (1993) con anticuerpos monoclonales específicos para antígenos de superficie. Se asignó el valor 0 cuando la tinción fue negativa (-), 0.5 cuando fue inconstante $( \pm), 1$ cuando fue ligera $(+), 2$ cuando fue moderada $(++)$ y 3 cuando fue fuerte $(+++)$.

\section{Análisis Estadístico}

Los datos del análisis de las imágenes se analizaron empleando el programa SPSS v. 19.0 para obtener la estadística descriptiva: media y moda. Los resultados fueron resumidos mediante tablas de frecuencias.

\section{Resultados}

La técnica de procesamiento inmunohistoquímico permitió, en todos los casos, la obtención de láminas de características óptimas para la evaluación semicuantitativa de las subpoblaciones de linfocitos en timos de alpacas menores a 60 días de edad. Asimismo, permitió observar la arquitectura y diferenciación entre corteza y médula, con una mayor densidad celular a nivel cortical (Figura 1). Sin embargo, la mayor población de células inmunomarcadas fue observada a nivel medular (Cuadro 2).

El resumen de la evaluación semicuantitativa (signos) de las subpoblaciones leucocitarias se muestra en el Cuadro 2. Se observa una mayor población de linfocitos TCR $\alpha \beta \gamma \delta(+++)$ en la médula, conformado por linfocitos TCR $\alpha \beta(++)$ y TCR $\gamma \delta(+)$, así como una menor población de linfocitos $\mathrm{B}$, monocitos y macrófagos $(+)$. Así mismo, los linfocitos T CD8, citotóxicos, se observaron en poca cantidad $(+)$, evidenciándose una población inconstante de linfocitos T CD4 colaborador (ver Figura 2). 
Cuadro 2. Distribución y densidad en corteza y médula de las poblaciones leucocitarias en timo de alpacas (Vicugna pacos) menores de 60 días de edad. Técnica de tinción inmunohistoquímica con anticuerpos monoclonales específicos para antígenos de superficie. Técnica de Avidin-Biotin-Peroxidasa y Hematoxilina

\begin{tabular}{|c|c|c|c|c|c|}
\hline $\begin{array}{l}\text { Anticuerpo } \\
\text { monoclonal }\end{array}$ & $\begin{array}{l}\text { Isotipo } \\
\text { Ig }\end{array}$ & $\begin{array}{c}\text { Cúmulo de } \\
\text { diferenciación }\end{array}$ & Corteza $^{1}$ & Médula $^{1}$ & $\begin{array}{l}\text { Patrón predominante de } \\
\text { expresión celular }\end{array}$ \\
\hline H58A & $\operatorname{IgG} 2 \mathrm{a}$ & CHM I & + & +++ & Pan leucocitos y plaquetas \\
\hline TH14B & $\operatorname{IgG} 2 \mathrm{a}$ & CHM II & - & +++ & $\begin{array}{l}\text { Linfocitos } \mathrm{B}, \\
\text { monocito/macrófagos, } \\
\text { linfocitos } \mathrm{T} \text { activados }\end{array}$ \\
\hline LT97A & $\operatorname{IgG} 2 b$ & $\mathrm{LC} 2$ & ++ & +++ & Linfocitos TCR $\alpha \beta \gamma \delta$ \\
\hline LT10A & $\operatorname{IgG} 2 \mathrm{a}$ & $\mathrm{LC} 1$ & + & ++ & Linfocitos TCR $\alpha \beta$ \\
\hline GB45A & $\operatorname{IgG} 1$ & BoWC1 & - & + & Linfocitos TCR $\gamma \delta$ \\
\hline LT5A & $\operatorname{IgG} 2 \mathrm{a}$ & $\mathrm{LaCD} 8$ & + & + & Linfocito T CD8 (citotóxico) \\
\hline GC50A & $\operatorname{IgM}$ & $\mathrm{LaCD} 4$ & - & \pm & $\begin{array}{l}\text { Linfocitos T CD4 } \\
\text { (colaborador) }\end{array}$ \\
\hline LH41A & $\operatorname{IgM}$ & - & - & + & Linfocitos B \\
\hline DH59B & $\operatorname{IgG} 1$ & SWC3 & \pm & + & $\begin{array}{l}\text { Granulocitos, } \\
\text { monocitos/macrófagos }\end{array}$ \\
\hline CAM36A & IgG1 & $\mathrm{LaCD} 14$ & - & + & $\begin{array}{l}\text { Monocitos/macrófagos, } \\
\text { granulocitos }\end{array}$ \\
\hline
\end{tabular}

${ }^{1}$ Tinción: negativa $(-)$, inconstante $( \pm)$, ligera $(+)$, moderada $(++)$, fuerte $(+++)$

En la zona cortical se observó una ligera presencia de linfocitos TCR $\alpha \beta$ y linfocitos TCD8, citotóxico, sin evidencias de monocitos / macrófagos, linfocitos B, linfocitos TCR $\gamma \delta$ y linfocitos T CD4, colaboradores (ver Cuadro 2, Figuras 2 y 3 ).

\section{Discusión}

En la visualización microscópica de las imágenes de timo se pudo observar el predominio de las células leucocitarias en la zona cortical sobre la zona medular. No obstante, es importante destacar que si bien la mayor población leucocitaria se observó a este nivel, determinado mediante el contraste nuclear con hematoxilina, esta población no correspondió a células inmunomarcadas con la IHQ. Al respecto, Zhao et al. (2001) descri- bieron en ovinos la presencia de pro-timocitos, que expresan $\mathrm{CD}^{+}$, marcador de superficie presente solo en linfocitos $\mathrm{T}$, que mantienen esta positividad hasta su madurez; asimismo describieron los timocitos TN CD3-, CD4- y CD8- que corresponden a una etapa muy inmadura de los timocitos, donde no expresan estos marcadores de superficie. Es así, que la población cortical observada, no inmunomarcada, correspondería a una población de timocitos en etapa inmadura.

Se ha descrito que los camellos presentan características únicas en su sistema inmune, tales como anticuerpos que carecen de cadenas livianas y solo compuestos de cadenas pesadas homodímeras (Muyldermans et al., 2009), características que también se presentan en los camélidos sudamericanos (De Genst et al., 2006; De Simone et $a l ., 2006)$. No hay descripción previa de po- 


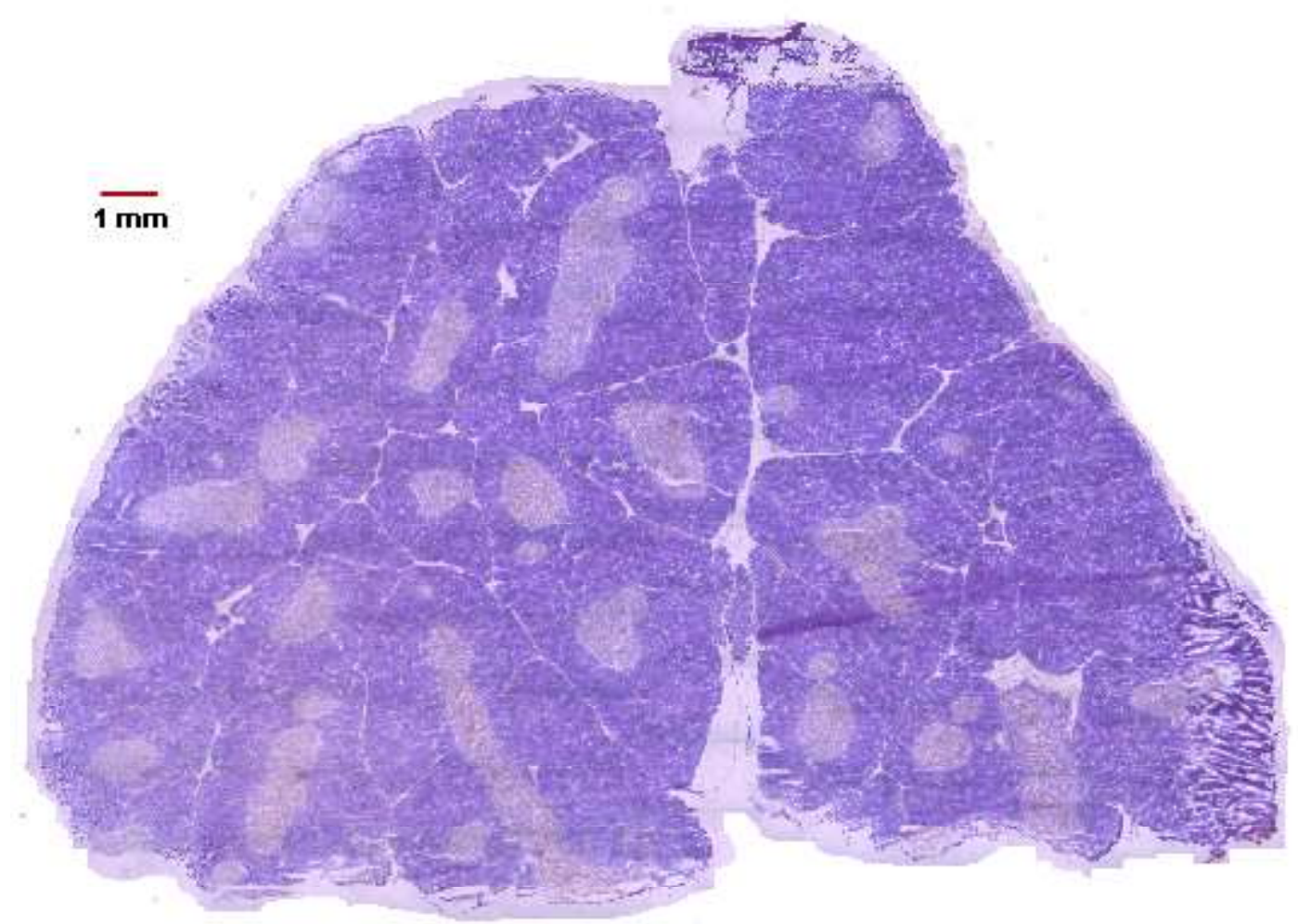

Figura 1. Imagen compuesta de timo de alpacas (Vicugna pacos) menores de 60 días de edad, mediante inmunohistoquímica. Técnica de Avidin-Biotin-Peroxidasa y Hematoxilina 40x. Se muestra la distribución histológica de corteza y médula del timo, con una alta densidad celular cortical en comparación a la médula

blaciones leucocitarias en timo de camélidos; sin embargo, han sido descritas las subpoblaciones leucocitarias circulantes en llamas; siendo muy similares a las descritas para camélidos del viejo mundo (Antonacci et al., 2011; Ciccarese et al; 2014) y a especies de rumiantes domésticos (Davis y Hamilton, 2006).

Las descripciones de la distribución de las poblaciones linfocitarias en el timo en diversas especies refieren que en la zona subscapular se ubican los linfocitos $\mathrm{CD}^{-} \mathrm{y}$ CD8-(DN), que en el parénquima cortical se ubican los linfocitos CD4 + y CD8+ (DP) y que en la zona medular se encuentran los de positividad simple, CD4 + o CD8+ (SP) (Davis y Hamilton, 2006; Montenegro et al., 2006, Pearse, 2006). Shortman (1985), con base a estudios en humanos y ratones, indicó que la distribución linfocitaria a nivel medular de linfocitos $\mathrm{CD}^{+}$corresponde al $5 \%$ y CD $4^{+}$ al $10 \%$, en tanto que el restante $80 \%$ corresponde a los CD4 + y CD8+ (DP), ubicados en la corteza tímica; sin embargo, también describe una población aún mucho más numerosa que las DP, que atañe a células CD4y CD8 $(\mathrm{DN})$, correspondiendo a precursores temprano de timocitos.

Sobre lo referido, las alpacas neonatas presentaron características propias en cuanto a la distribución de estas subpoblaciones, mostrando un predominio de linfocitos $\mathrm{CD}^{+}$ $(+)$ sobre los $\mathrm{CD}^{+}( \pm)$a nivel medular; no evidenciando $\mathrm{CD}^{+}$a nivel cortical a diferencia de lo descrito por Shortman (1985) quien indica un predominio de población de linfocitos $\mathrm{CD}^{+}$sobre linfocitos $\mathrm{CD} 8^{+}$a este nivel en el humano y el ratón. 

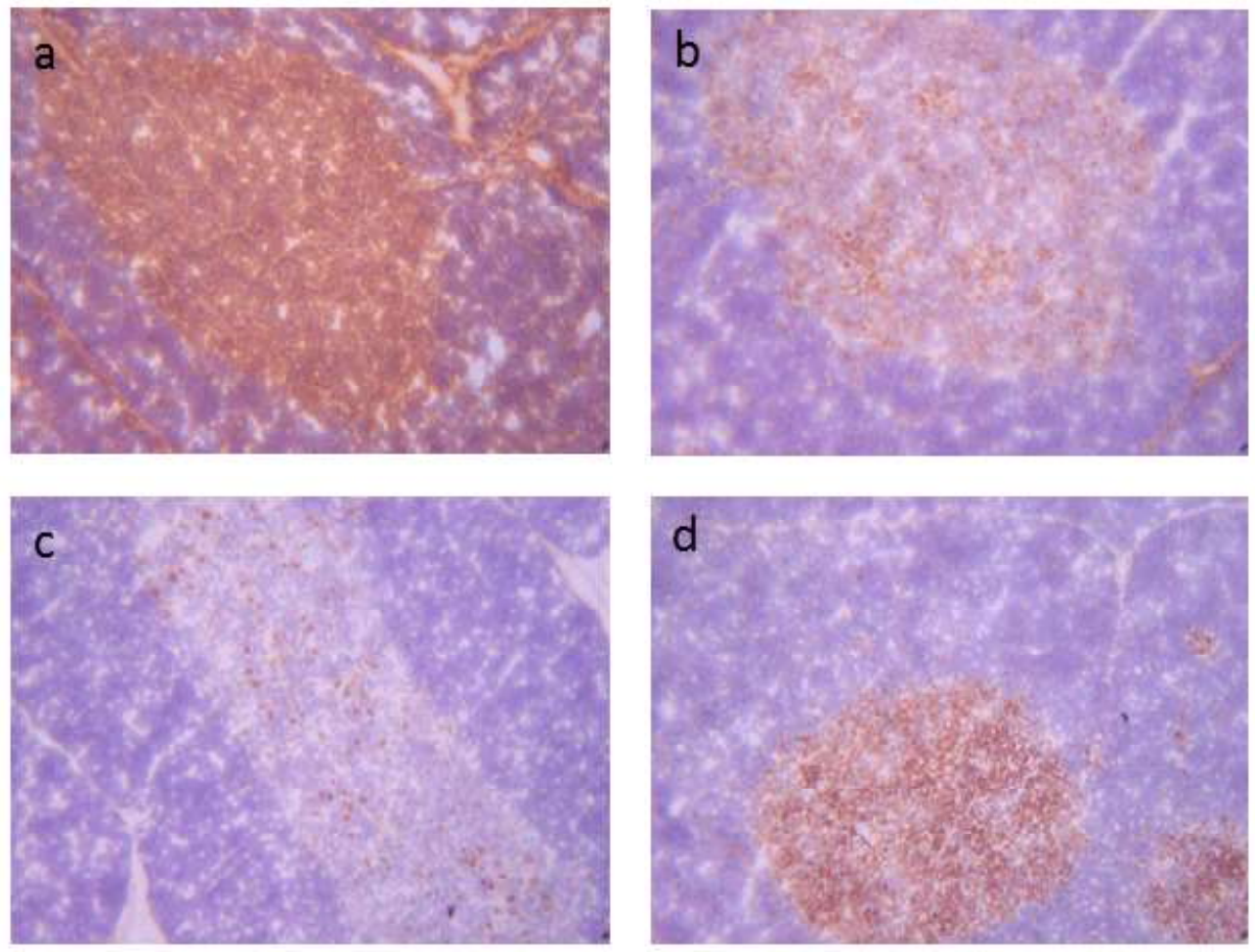

Figura 2. Imágenes de técnica de tinción inmunohistoquímica con anticuerpos monoclonales específicos para antígenos de superficie. Técnica de Avidin-Biotin-Peroxidasa y Hematoxilina en timo de alpacas (Vicugna pacos) menores de 60 días de edad. 400x (a) H58A. Pan leucocitos y plaquetas; (b) DH59B. Granulocitos, monocitos/macrófagos; (c) CAM36A. Monocitos/macrófagos, granulocitos; (d) TH14B. Linfocitos B, monocito/ macrófagos, linfocitos $\mathrm{T}$ activados

En relación a la expresión de receptores de linfocitos, se ha descrito que linfocitos TCR $\alpha \beta$ corresponden a linfocitos CD4 +o $\mathrm{CD} 8+(\mathrm{SP})$ y linfocitos CD4 + y CD8+ (DP) (Davis y Hamilton, 2006; De Genst et al., 2006; Montenegro et al., 2006). En referencia a ello, los resultados del presente estudio muestran que los TCR $\alpha \beta$ predominaron en la región medular $(++)$ sobre la cortical $(+)$; siendo este resultado esperado ya que los TCR áâ corresponden a linfocitos CD4 + o CD8+ (SP), conservando la distribución ya descrita para esta subpoblación. Al respecto, Godderis (1989) describió en bovinos que en la médula tímica predominan los simples positivos $\mathrm{CD} 4^{+}, \mathrm{CD} 8^{+}$y los TCR $\gamma \delta$.
Los linfocitos que expresan TCR $\gamma \delta$ correspondieron a linfocitos $\mathrm{CD}^{-}$y CD8 $8^{-}(\mathrm{DN})$ (Davis y Hamilton, 2006; De Gents et al., 2006; Montenegro et al., 2006), observándose en el presente estudio solo una baja población de estos linfocitos a nivel medular; como lo describe Godderis (1989) en terneros donde observa entre 5 a $15 \%$ TCR $\gamma \delta$ a este nivel, correspondiendo al centro de diferenciación y maduración de esta población linfocitaria. Al respecto, Davis et al. (2000) y Ciccarese et al. (2014) indican que la población a nivel sérico de linfocitos $\mathrm{T} \gamma \delta \mathrm{TCR}$ en rumiantes, cerdos y camélidos del viejo mundo, muestran que están compuestas de 

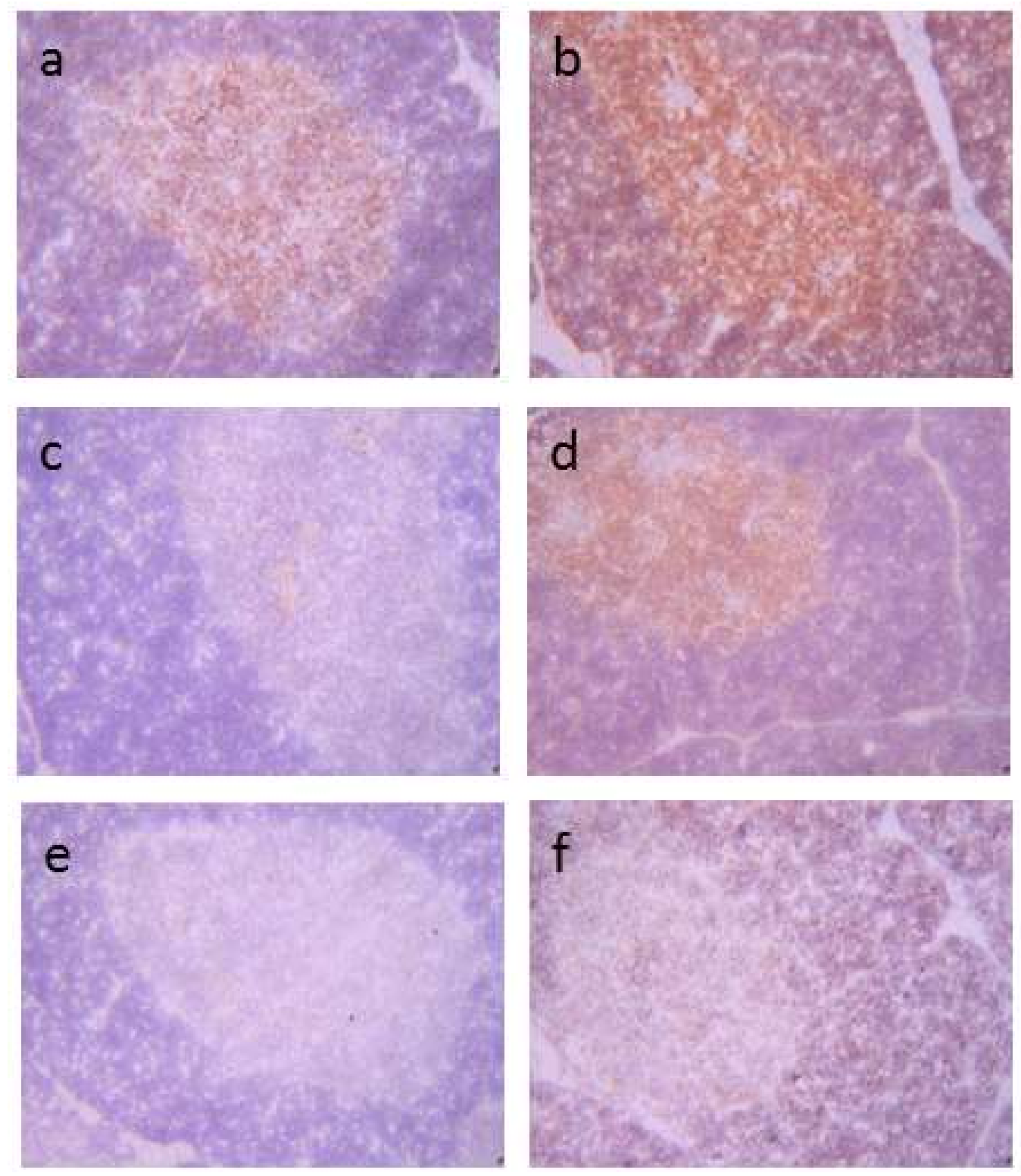

Figura 3. Imágenes de técnica de tinción inmunohistoquímica con anticuerpos monoclonales específicos para antígenos de superficie. Técnica de Avidin-Biotin-Peroxidasa y Hemtoxilina en timo de alpacas (Vicugna pacos) menores de 60 días de edad. 400x. a) LH41A. Linfocitos B; b) LT97A. Células TCR $\alpha \beta \gamma \delta$; c) GB45A. Linfocitos TCR $\gamma \delta$; d) LT10A. Linfocitos TCR $\alpha \beta$; e) GC50A. Linfocitos T CD4 (colaborador); f) LT5A. Linfocito T CD8 (citotóxico)

dos complejas poblaciones que difieren en su distribución en tejidos; teniendo como funciones principales el reconocimiento de los antígenos no peptídicos, de PAMPs, de DAMPs, y antígenos no procesados, no de- pendiendo de la co-estimulación de las células presentadoras de antígeno, optimizando el desarrollo de una respuestas rápida (Davis et al., 1998; Hayes et al., 2010; Guzmán et al., 2012; Telfer y Baldwin, 2015). 
El presente estudio determinó una escasa población de linfocitos $\mathrm{B}$, monocitos $\mathrm{y}$ macrófagos a nivel de la médula del timo, $\mathrm{y}$ una inconstante presencia de monocitos y macrófagos en corteza. Ferrero et al. (1999) y Flores et al. (2001) describen que estas células se encuentran confinadas en la médula tímica y que las células dendríticas, los linfocitos B y las células epiteliales reticulares medulares juegan un papel importante en la selección negativa de los linfocitos T. Asimismo, se ha descrito que los macrófagos participan en fagocitosis de los linfocitos apoptósicos que son originados en este proceso de segregación (Miliæeviæ et al., 2014; Szondy et al., 2012).

\section{Conclusiones}

- La mayor población de células leucocíticas se ubicaron en la corteza del timo y correspondieron a células inmaduras que no expresan marcadores de superficie.

- La mayor población de células inmunomarcadas en maduración se ubicaron en la médula del timo, predominando los linfocitos TCR $\alpha \beta$, con valores bajos de linfocitos TCR $\gamma \delta$, linfocitos CD8, linfocitos B y monocitos/ macrófagos; con valores inconstantes de linfocitos CD4.

- En la corteza del timo se observó valores bajos de linfocitos TCR $\alpha \beta$ y linfocitos $\mathrm{CD} 8$, y valores inconstantes de monocitos/macrófagos; sin evidencias de linfocitos TCR $\gamma \delta$, linfocitos CD4 y linfocitos B.

\section{Agradecimientos}

El estudio fue implementado con el apoyo financiero de International Foundation for Sciences a través del Grant B/3639-1 del Proyecto «Development and maturation of immune system of alpacas neonates (Lama pacos)».

\section{Literatura Citada}

1. Ameghino E. 1991. Causas de mortalidad en crías de alpaca. En: FernándezBaca S (ed). Avances y perspectivas del conocimiento de los camélidos sudamericanos. Santiago de Chile: FAO.p 149-200.

2. Antonacci R, Mineccia M, Lefranc M$P$, Ashmaouic HME, Lanave $C$, Piccinni B, Pesole G, et al. 2011. Expression and genomic analyses of Camelus dromedarius $\mathrm{T}$ cell receptor delta (TRD) genes reveal a variable domain repertoire enlargement due to CDR3 diversification and somatic mutation. Mol Immunol 48: 1384-1396. doi: 10.1016/j.molimm.2011.03.011

3. Arias W, Sandoval N, Chavera A, Manchego A. 2011. Caracterización de la citoarquitectura esplénica fetal de alpacas (Lama pacos). Rev Inv Vet Perú 22: 81-88. doi: 10.15381/ rivep.v22i2.273

4. Bolant B, Calvo M A, Cejalvo D, Gimeno LO, Gimeno L, Lloris J M.1990. La eutanasia en los animales de laboratorio. Res Surgery Supl 5: 45-56.

5. Capri M, Quaglino D, Verzella G, Monti D, Bonafe M, Cossarizza A, Troiano L, et al. 2000. A cytofluorimetric study of $\mathrm{T}$ lymphocyte subsets in rat lymphoid tissues (thymus, lymph nodes) and peripheral blood: a continuous remodelling during the first year of life. Exp Gerontol 35: 613-625. doi: 10.1016/S0531-5565(00)00107-8

6. Carlson BM. 1990. Embriología básica de Patten. $5^{\circ}$ ed. México DF: Interamericana McGraw-Hill. $770 \mathrm{p}$.

7. Chilmonczyk S. 1992. The thymus in fish: development and possible function in the immune response. Annual Rev Fish Dis 2: 181-200. doi: 10.1016/09598030(92)90063-4

8. Ciccarese S, Vaccarelli G, Lefranc MP, Tasco G, Consiglio A, Casadio R, Linguiti $G$, et al. 2014. Characteristics of the somatic hypermutation in the Camelus dromedarius $\mathrm{T}$ cell receptor 
gamma (TRG) and delta (TRD) variable domains. Dev Comp Immunol 46: 300-313. doi: 10.1016/j.dci.2014.05.001

9. Davis WC, Heirman LR, Hamilton MJ, Parish SM, Barrington GM, Loftis $A$, et al. 2000. Flow cytometric analysis of an immunodeficiency disorder affecting juvenile llamas. Vet Immunol Imunopathol 74: 103-120. doi: 10.1016/ S0165-2427(00)00167-7

10. Davis WC, Zuckermann FA, Hamilton MJ, Barbosa JIR, Saalmüller A, Binns RM, Licence ST. 1998. Analysis of monoclonal antibodies that recognize $\gamma \delta \mathrm{T} /$ null cells. Vet Immunol Imunopathol 60: 305-316. doi: 10.1016/ S0165-2427(97)00107-4

11. Davis WC, Hamilton MJ. 2006. Use of flow cytometry to characterize immunodeficiency syndromes in camelids. Small Ruminant Res 61: 187193. doi: 10.1016/j.smallrum-res.2005.07.008

12. De Genst E, Saerens D, Muyldermans $S$, Conrath K. 2006. Antibody repertoire development in camelids. Dev Comp Immunol 30: 187-198. doi: 10.1016/ j.dci.2005.06.010

13. De Lamo DA. 2011. Camélidos sudamericanos: historia, usos y sanidad animal. Buenos Aires, Argentina: SENASA. 51 p.

14. De Simone EA, Saccodossi N, Ferrari A, Leoni J. 2006. Immunochemical analysis of Ig G subclasses and IgM in South American camelids. Small Ruminant Res 64: 2-9. doi: 10.1016/ j.smallrumres.2005.03.009

15. Dellmann HD, Brown EM. 1980. Histología veterinaria. Zaragoza: Acribia. $529 \mathrm{p}$.

16. Enciso J. 1995. Patología molecular: aspectos básicos. Avances Med Vet 10: 1624. doi: 10.5354/0719-5273.2010.10435

17. Ferrero I, Anjuère F, Martín P, Martínez del Hoyo G, López, M, Wright $N$, Varona $R$, et al. 1999. Functional and phenotypic analysis of thymic B cells: role in the induction of $\mathrm{T}$ cell negative selection. Eur J Immunol 29: 1598-1609. doi: 10.1002/(SICI)1521-4141(199905)-
29:0 5<1598:: A ID - IMMU 15 98>3.0.CO;2-O

18. Flores KG, Li J, Hale LP. 2001. B Cells in epithelial and perivascular compartments of human adult thymus. Hum Pathol 32: 926-934. doi: 10.1053/ hupa.2001.27106

19. Galeotti M, Sarli G, Eleni C, Marcato PS. 1993. Identification of cell types present in bovine haemolymph nodes and lymph nodes by immunostaining. Vet Immunol Immunopathol 36: 319-331. doi: 10.1016/0165-2427(93)90028-3

20. Godderis B. 1989. Immunology of cattle, lympoid organs. In: Pastorer PP, Griebel P, Bazin H, Govaerts A (eds). Handbook of vertebrate immunology. UK: Academic Press. p 439-444.

21. Guzman E, Price S, Poulsom H, Hope J. 2012. Bovine $\gamma \delta \mathrm{T}$ cells: cells with multiple functions and important roles in immunity. Vet Immunol Immunopathol 148: 161-167. doi: 10.1016/j.vetimm.2011.03.013

22. Hayes SM, Laird RM, Love PE. 2010. Beyond $\alpha \beta$ / $\gamma \delta$ lineage commitment: TCR signal strength regulates $\gamma \delta$ T cell maturation and effector fate. Semin Immunol 22: 247-251. doi: 10.1016/ j.smim.2010.04.006

23. Haynes B, Fauci A. 2006. Trastornos del sistema inmunitario. En: Harrison. Principios de medicina interna. $16^{\circ}$ ed. Madrid: McGraw Hill Interamericana. $p$ 2009-2125.

24. Hinostroza R. Manchego A, Sandoval N. Chiok KL, More J. 2015. Expresión de citocinas pro-inflamatorias de leucocitos de alpaca (Vicugna pacos) inducidos por el extracto de macroquistes de Sarcocystis aucheniae. Rev Inv Vet Perú 26: 328-341. doi: 10.15381/ rivep.v26i2.11007

25. [INEI] Instituto Nacional de Estadística e Informática. 2012. Resultados definitivos. IV Censo Nacional Agropecuario 2012. $62 \mathrm{p}$.

26. Latre MV, Bárcena MC. 2007. Órganos y tejidos implicados en la respuesta inmune: En: Gómez-Lucia E, del Mar 
Blanco M. Manual de inmunología veterinaria. Madrid: Pearson Prentice Hall. p. 21- 40.

27. Miliaeeviae NM, Laliae IM, Despotoviae SZ, Airice D, Westermann J, De Waal Malefyt R, Miliceevice Z. 2014. Aberrant Tissue positioning of metallophilic macrophages in the thymus of XCL1-deficient mice. Anat Rec 297:1472-1477. doi: 10.1002/ar.22935

28. Montenegro J, Sandoval N, Chavera A, Manchego A. 2006. Caracterización histológica del timo en fetos de alpaca. Rev Inv Vet Perú 17: 26-32. doi: 10.15381/rivep.v17i1.1454

29. Muyldermans S, Baral TN, Cortez V, De Baetselier P, De Genst E, Kinne J, Leonhardt $\mathrm{H}$, et al. 2009. Camelid immunoglobulins and nanobody technology. Vet Immunol Immunopathol 128: 178-183. doi: $10.1016 /$ j.vetimm.2008.10.299

30. Noden DM, De Lahunta A. 1990. Embriología de los animales domésticos. Zaragoza: Acribia. 399 p.

31. Pearse G. 2006. Normal structure, function and histology of the thymus. Toxicol Pathol 34: 504-514. doi: 10.1080/ 01926230600865549

32. Roca V, Manchego A, Sandoval N, Chiok KL Rivera H. 2014. Caracterización histológica y dinámica linfoide de las placas de Peyer en crías de alpaca durante los 45 primeros días de vida. Rev Inv Vet Perú 25: 341-349. doi: 10.15381/ rivep.v25i3.10112

33. Rosadio R, Maturrano L, Pérez D, Luna L. 2012. El complejo entérico neonatal en alpacas andinas. Rev Inv Vet Perú 23: 261-271. doi: 10.15381/ rivep.v23i3.908

34. Shortman K. 1985. What the papers say: early steps in T lymphocyte development within the thymus. Bioessays 2: 215-216. doi: 10.1002/bies.950020508

35. Szondy Z, Garabuczi E, Tóth K, Kiss B, Köröskényi K. 2012. Thymocyte death by neglect: contribution of engulfing macrophages. Eur J Immunol 42: 16621667. doi: 10.1002/eji.201142338

36. Telfer JC, Baldwin CL. 2015. Bovine gamma delta $\mathrm{T}$ cells and the function of gamma delta $\mathrm{T}$ cell specific WC1 coreceptors. Cell Immunol 296: 76-86. doi: 10.1016/j.cellimm.2015.05.003

37. Vaidya HJ, Briones Leon A, Blackburn C. 2016. FOXN1 in thymus organogenesis and development. Eur J Immunol 46: 1826-1837. doi: 10.1002/eji.201545814

38. Zhao T, He Ch, Su M, West CA, Swanson SJ, Young AJ, Mentzer SJ. 2001. Cell adhesion molecule expression in the sheep thymus. Dev Comp Immunol 25: 519-530. doi: 10.1016/ S0145-305X(01)00006-4 